\title{
Survival Outcome in Patients with Cardiomyopathy Detected by Gated SPECT Myocardial Perfusion Imaging

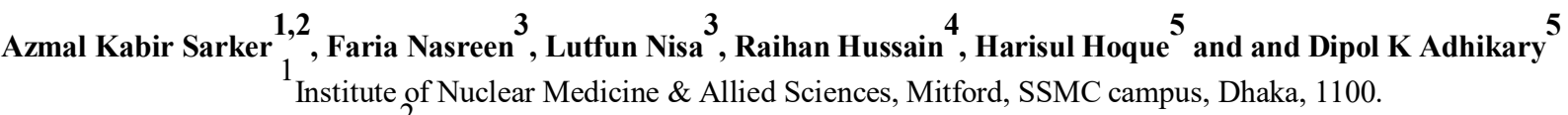 \\ Institute of Nuclear Medical Physics, AERE campus, Savar \\ 3 National Institute of Nuclear Medicine \& Allied Sciences, BAEC, Bangabandhu Sheikh Mujib Medical University campus, Shahbag, Dhaka, 1000. \\ ${ }_{5}^{4}$ Department of Nuclear Medicine, Apollo Hospitals, Plot 81, Block E, Bashundhara, Dhaka, 1229 \\ Department of Cardiology, Bangabandhu Sheikh Mujib Medical University, Shahbag, Dhaka, 1000.
}

Correspondence Address: Azmal Kabir Sarker, Institute of Nuclear Medicine \& Allied Sciences, Mitford, Dhaka. Email aksninmas@gmail.com

\begin{abstract}
Objectives: Quantitative assessment of $L V$ dysfunction and viability through gated SPECT myocardial perfusion imaging (GSMPI) in addition to being diagnostic surrogate of cardiomyopathy (CM), are being increasingly reported as a predictor of adverse outcome in CM. This study was conducted to investigate the survival outcome in patients diagnosed with CM by GSMPI at National Institute of Nuclear Medicine \& Allied Sciences (NINMAS).

Patients and methods: Patients who underwent Tc-99m Sestamibi GSMPI at NINMAS from January 2007 to December 2009 and were diagnosed with $\mathrm{CM}$ were retrospectively included in the study. The GSMPI parameters of diagnosis of $\mathrm{CM}$ were a left ventricular ejection fraction (EF) at rest of less than $40 \%$ with a corresponding end diastolic left ventricular volume (EDV) of more than $130 \mathrm{ml}$. Telephonic interviews of those patients were conducted in the year 2015 to obtain their clinical follow up data.

Results: Fifty two patients $(\mathrm{M} / \mathrm{F}=50 / 2)$ were diagnosed to have CM over a period of three years. Follow up data of 19 $(\mathrm{M} / \mathrm{F}=18 / 1)$ patients with mean age 52.9 \pm 7.4 (38-65), EF 29.1 \pm 6.6 (18-39), EDV 211 \pm 45.4 (135-320) were available. Nine (47.4\%) patients were alive at the time of follow up and $10(52.6 \%)$ patients were found to be deceased. Thus, in this patient group one and five year survival was estimated to be 68 and $47 \%$. Comparison of means of pretest probability score, GSMPI parameters of $L V$ function and viability revealed no difference $(p>0.05)$ between survivors and non-survivors. Test of equality of survival distributions for management strategies revealed no difference either (Log Rank significance, $p>0.05)$.
\end{abstract}

Conclusions: Five year survival in this study group diagnosed with CM by GSMPI was $47 \%$ where pretest probability score, GSMPI parameters and management strategies were not associated with difference of survival.

Key Words: Survival, cardiomyopathy, gated SPECT, myocardial perfusion, Bangladesh.

Bangladesh J. Nucl. Med. Vol. 21 No. 2 July 2018

Doi: https://doi.org/10.3329/bjnm.v21i2.40356

\section{INTRODUCTION}

Cardiomyopathy (CM) is characterized by left ventricular (LV) dilatation and LV systolic dysfunction (1) which progresses inexorably to heart failure (HF) $(2,3) . \mathrm{CM}$, in advanced countries contributes up to $40 \%$ of the proportion of total patients with HF (4). Banerjee et al. reports HF in $75 \%$ patients and death during hospital stay in $8 \%$ patient with CM (5). HF causes decline in quality of life (6) with an observed 5-year survival of $26-52 \%$ (7) and thus it is labeled as more malignant that cancer (8). While HF is being increasingly detected in Asian countries reaching a prevalence of $1.5 \%$ (9), improved survival outcome is being reported with appropriate management $(10,11)$.

LV ejection fraction (LVEF), end systolic volume (ESV), ESV index (ESVI) and LV scar percentage has been reported to be predictors of adverse outcome in CM (12-14). Gated SPECT myocardial perfusion imaging (GSMPI) with nitrate enhancement using Tc-99m Sestamibi is a validated technique for evaluation of LV dysfunction (15-17) as well as for prediction of survival outcome in patients with ischemic CM (18), and has been an associate to management of ischemic heart disease (IHD) in Bangladesh since 2001(19).

To our best knowledge there is no report of survival rates among patients with severe LV dysfunction or $\mathrm{CM}$ in Bangladesh. Thus the aim of the study was to assess the long term survival outcome in patients after 
they were diagnosed with severe LV dysfunction or CM based on GSMPI finding of LV dilatation and low LVEF.

\section{PATIENTS AND}

\section{METHODS Study patients}

This was a cross sectional retrospective study conducted in the year, 2015 on a group of patients who were referred to Nuclear Cardiology Division of National Institute of Nuclear Medicine and Allied Sciences (NINMAS) from January 2007 to December 2009 for GSMPI as a part of work up for CAD at its different stages. The patients who had been diagnosed with CM by GSMPI within that period were selected. The diagnostic criteria of CM was LVEF at rest of less than $40 \%$ with a corresponding end diastolic left ventricular volume (EDV) of more than $130 \mathrm{ml}$. Among the patients with $\mathrm{CM}$ only those were included in the final analysis whose follow up data were available till end of study.

\section{Data extraction}

Record files of GSMPI of all patients with CM were obtained from the Nuclear Cardiology Division's patient studies in order to retrieve their demographic data including the contact numbers. A retrospective calculation of pretest probability of CAD was done for each patient by inputting their age, sex and risk factors using an online calculator QxMD. All patients had undergone GSMPI in a dual head gamma camera (Siemens e.cam). Radiotracer used was Tc-99m Sestamibi. The LVEF, EDV, ESV and LV scar percentage at rest including the summed rest score (SRS) of each patient were estimated using 4DMSPECT.

\section{Follow up}

The patients were called up by a physician who conducted a semi structured interview over telephone to obtain the clinical follow up data of those patients. Physician could talk either directly with the patients or with a family member of a deceased patient. Information regarding improvement or decline of patient's quality of life in comparison to patient's status prior to GSMPI was obtained. Mode of managements within these years was enquired. If the patient was reported as dead by a family member, they were asked to provide the date and place of death. They were also asked to provide hospital's comment about cause of death if it was a case of death in hospital.

Study endpoints, variables and analytic method

Death of a patient was considered as the only final event in the survival analysis. Events were taken into account until 30 June of 2015, the date the study ended. The time from the diagnosis of CM to death was analyzed with the Kaplan-Meier method. Other quantitative variables were expressed by appropriate summary statistics i.e. using mean \pm standard deviation (SD) and value ranges or median. The results of the qualitative variables were given as percentages. Comparison of quantitative variables between survivors and non-survivors were done using independent samples $\mathrm{T}$ test. Comparison of categorical variables between survivors and nonsurvivors were done using Log Rank (Mantel-Cox) test. SPSS software version 20 (SPSS Inc. Chicago, IL, USA) was used for the statistical analyses. Twotailed $p$ value of $<0.05$ was considered statistically significant, when appropriate.

\section{RESULTS}

\section{Demographic and clinical characteristics}

From January 2007 to December 2009, a total of 879 patients underwent GSMPI at NINMAS where 52 (6\%) patients aged 32 to 75 years were diagnosed to have CM on the basis of EDV and LVEF measurements obtained from GSMPI. Among them 50 were male and two were female. Mean age for these patients was $51.6 \pm 9.5$ years with mean LVEF $27.7 \pm 5.5$ (18-39) and mean EDV $223 \pm 69.7$ (135486). In July 2015 when the follow up telephonic interviews were conducted, follow up data of 19 out of $52(37 \%)$ patients were available.

Thus, 19 patients were followed for a median period of 48 months. Among them 18 were male and one was 
female with mean of age 52.9 \pm 7.4 years with the range being 38-65 years. The mean pre-test probability of having $\mathrm{CAD}$ in 19 patients was calculated retrospectively to be, $46.9 \pm 15.4 \%$ with the range being $13-70 \%$. Eleven patients were in the category of high probability and remaining eight were in the category of intermediate probability. The indication of referral for GSMPI in 16 among 19 patients was assessment of myocardial viability with history of myocardial infarction while the other three were sent for assessment of revascularization with a history of prior revascularization. Findings of coronary angiogram were triple vessels disease in 11, double vessels disease in five and single vessel disease in three. All patients had abnormal wall motion on echocardiogram. Fourteen patients underwent rest only GSMPI while four underwent adenosine stress and one underwent dobutamine stress.

GSMPI revealed extensive fixed perfusion defect in all patients with mean proportion of total LV involved (\%) was $54.5 \pm 6.4$ with the range being $44-68 \%$. Mean of summed rest perfusion score (SRS) was 29.3 \pm 5.3 where the range was 22-39. Mean LV parameters at rest were: ESV (ml) 151.5 \pm 38.7 (range 87-266 ml), LVEF (\%) $29.1 \pm 6.6$ (range 18-39\%) and EDV (ml) 211.2 \pm 45.4 (range 135-320 ml). Figure 1 shows a representative image of GSMPI in a patient with CM. Mean ESVI $(\mathrm{ml} / \mathrm{m} 2)$ was $75.1 \pm 19.4$ (range $40.9-105.2 \mathrm{ml} / \mathrm{m} 2)$.

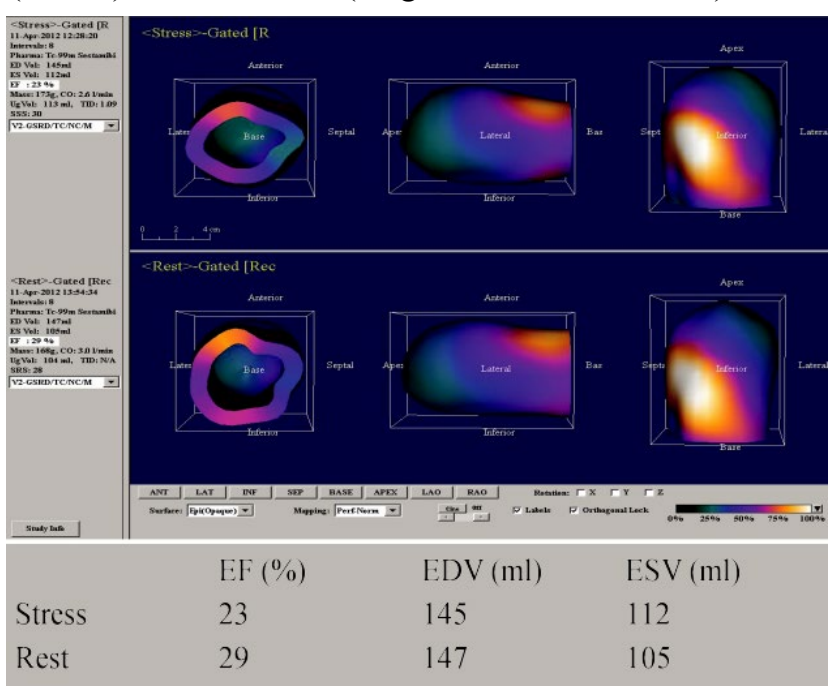

Figure 1: Representative LVEF and EDV measurement in a 57 years old male $L V E F<40 \%$ ) and corresponding EDV $>130 \mathrm{ml}$, as measured by GSMPI
During the follow up period, 15 patients received exclusive medical management (MM) only while four patients had undergone coronary revascularization $(\mathrm{CR})$ in addition to $\mathrm{MM}$.

\section{Overall survival}

Nine (47.4\%) patients (m/f: $8 / 1)$ were alive at the time of follow up after five years and 10 (52.6\%) patients (all male) were found to be deceased. Six patients died within first year, one by second year, one by third year and two by fourth year. In this small group the one year survival was estimated to be $68 \%$. All cause mortality for the entire study group was $42 \%$ during 3 years and $53 \%$ during the median follow up period of four years. Death of two was associated with non cardiac illness (one with multi-organ failure and the other with ischemic stroke); death of four was associated with heart failure and the other four patients died at home. Finally, the five year survival in the study group was estimated to be $47 \%$ (Figure 2)

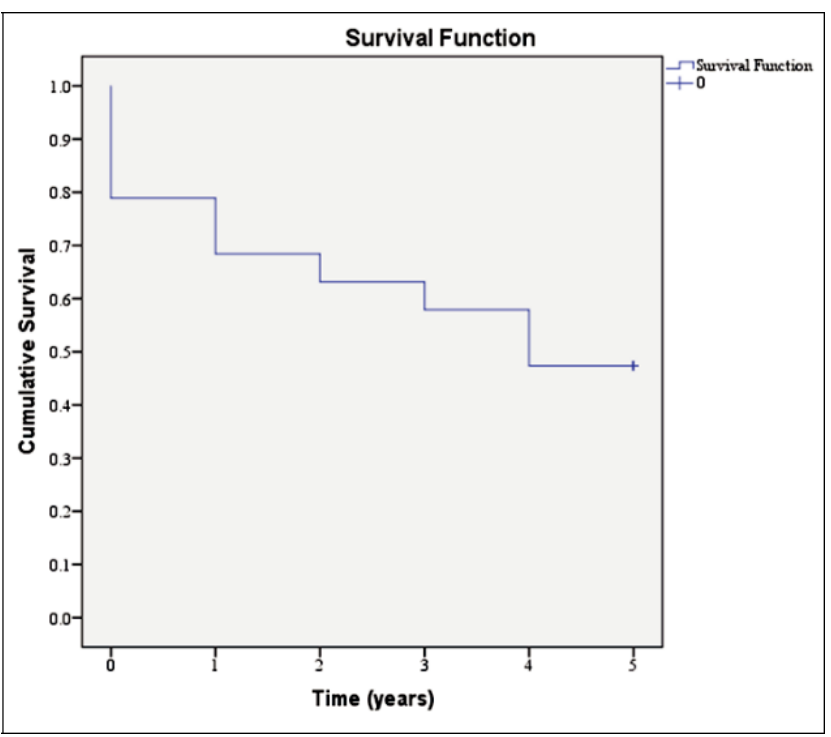

Figure 2: Survival plot for 19 patients with cardiomyopathy showing their cumulative survival against time.

Comparison of variables among survivors and deceased

Independent samples $\mathrm{T}$ test revealed no significant difference of mean age, pre test probability score, proportion of total LV involved with perfusion defect, 
SRS, ESV, EDV or LVEF among the alive and deceased; however the difference of mean LVEF (echo) reached a statistical significance (Table 1).

Pre test probability of having CAD was estimated to be intermediate in four of 10 deceased and in four of nine alive during follow up. Thus the test of equality of survival distributions between intermediate and high pretest probability of having CAD revealed no difference with the Log Rank significance, $\mathrm{p}>0.05$ (Table 1).

Table 1: Characteristics in patients $(n=19)$ who were followed up.

\begin{tabular}{|c|c|c|c|c|}
\hline Characteristics & $\operatorname{Died}(n=10)$ & Alive $(n=9)$ & Significance & $95 \% \mathrm{CI}$ \\
\hline Age & $53.7=8.8$ & $52.1=6$ & $0.66^{*}$ & $-5.8-8.9$ \\
\hline Prelest probability (clinical model) & $49.80 \pm 17.9$ & $43.8=12.1$ & $0.41^{*}$ & $-8.9-21$ \\
\hline Pretest probability of having CAD (qualitative) & & & $0.73 \dagger$ & \\
\hline Tntermediate pretest probability & $n=4$ & $n=4$ & 0.687 & $1.9-4.6$ \\
\hline Iligh pretest probability & $n=6$ & $n=5$ & $0.66 \hbar$ & $1.8-4.4$ \\
\hline Proportion of total LV involved (\%) & $54.1-7.8$ & $54.9-4.7$ & $0.79^{*}$ & $-7.1-5.5$ \\
\hline SRS & $30.0-5.9$ & $26.5-0.7$ & $0.14^{*}$ & $-1.4-8.4$ \\
\hline ESV & $159+45.2$ & $143.2-30.7$ & $0.39 *$ & $-22.1-53.6$ \\
\hline ESVI & $76.2=14.5$ & $74.3=23.4$ & $0.88^{*}$ & $-22.6-26.3$ \\
\hline EDV & $220.2 \pm 48.5$ & $201.2=42.2$ & $0.38^{*}$ & $-25.3-63.2$ \\
\hline EF (MPI) & $28.7=6.8$ & $29.6=6.7$ & $0.79^{*}$ & $-7.4-5.7$ \\
\hline $\mathrm{EF}$ (Echo) & $29.9=4.2$ & $36.1=5.5$ & $0.02^{*}$ & $-1.4--1.3$ \\
\hline Management strategy & & & $0.38 \dagger$ & \\
\hline Yedical management & $n=6$ & $n=7$ & $0.56 t$ & $1.9-4.2$ \\
\hline Revasculari/ation & $n=4$ & $\mathrm{n}=2$ & 0.837 & $1.9-5.1$ \\
\hline
\end{tabular}

*T-test 2-tailed significance, $\nmid$ Log Rank (Mantel-Cox) significance, ${ }_{\dagger}$ Standard Error

Among the four patients who underwent CR plus MM after imaging, two had died within three years (EF 26 and 39\%, EDV 193 and 144ml). Among the other 15 patients who were on exclusive MM, eight died within four years. CR plus MM was the management strategy in two of 10 deceased and in two of nine alive during follow up. Test of equality of survival distributions for two different treatment strategies thus revealed no difference (Log Rank significance, $p>0.05$ ).

\section{DISCUSSION}

The impartiality of survival outcome across the treatment strategies in our study in patients with LVEF $<40 \%$ contradicts with reports claiming an improved survival outcome following $\mathrm{CR}$ in comparison to $\mathrm{MM}$ alone in patients with $\mathrm{LV}$ dysfunction where one group of subjects have $\mathrm{LVEF}<25 \%$ (20) and the other have $\mathrm{LVEF} \leq 40 \%$ (21). The Surgical Treatment for Ischemic Heart Failure (STICH) trial in patients with LV dysfunction $(E F \leq 35 \%)$ finds no statistically significant difference between MM alone versus MM plus CR with respect to any cause mortality (22).

In our small series, the distribution of GSMPI parameters LV viability viz. proportion of total LV involved and SRS were not different among the survivors and non-survivors. This is somewhat similar to the STICH viability sub-study that do not find a significant interaction between viability status and treatment assignment with respect to mortality (23). However, a meta-analysis (24) suggests that the indifference in mortality with $\mathrm{CR}$ versus $\mathrm{MM}$ is imparted by absence of myocardial viability which was detected by nuclear imaging or inotrope stress echocardiography. Absence of viability was quantified using scar burden and ESVI and was reported to be aggravator of mortality risk, irrespective of $\mathrm{CR}$ or $\mathrm{MM}$, in patients with ischemic CM with mean LVEF of $23 \%$, (13). Another metaanalysis suggests $38.7 \%$ as the optimum quantity of viable LV myocardium, as assessed by Tc- $99 \mathrm{~m}$ Sestamibi GSMPI to be associated with improved functional recovery leading to improved survival outcome after CR in comparison to MM (25).

\section{Limitations of the study:}

Demographic characteristics and risk factors were converted to pre-test probability in order to assess the difference of their distribution of among survivors and non-survivors. The apparent difference in mean was however statistically not significant possibly due to small sample size. Analysis of LV viability weighted against factors like poorly controlled diabetes or renal insufficiency could be of value in a larger sample size. Inclusion and analysis of more traits viz. NYHA functional class of symptoms, rest ECG features, brain natriuretic peptide, patient's compliance to treatment and life-style modification advice was not possible due to retrospective nature of this study. 
Though we could obtain confirmation of alive status with generalized information on management strategy or place and date of death through a telephonic interview, patient follow up data weren't obtained from any standard source such as death register or hospital record. Thus a reliable determination of disease progression, regression or exact diagnosis at death wasn't attainable. Two point assessment of LV function was beyond the scope of this study.

Also the entire study may be considered biased because the data for the other $63 \%$ patients was not available, which might have changed both the survival proportion and the 'indifferent' scenario across all the parameters analyzed. Thus there is future scope for exploring the exact reality of both survival proportion and influence of different management strategies on survival in a larger series of patient.

\section{CONCLUSIONS}

The present study in a small group of patients with $\mathrm{CM}$ having $\mathrm{LVEF}<40 \%$ and $\mathrm{LV}$ EDV $>130 \mathrm{ml}$ as quantified by GSMPI, could find 'no difference' of survival outcome irrespective of clinical parameters converted to quantifiable pre-test probability score, GSMPI quantitative parameters of LV function \& viable myocardium and finally between treatment strategies. However, it may be permitted to assume that a diagnosis of CM using GSMPI quantitative parameters of LV dysfunction and viability can be a predictive indicator of poor survival outcome irrespective of treatment strategy in patients with $\mathrm{CM}$ in Bangladesh.

\section{DISCLOSURE}

No competing financial interests exist

\section{ACKNOWLEDGEMENT}

Authors acknowledge the collaborative contribution of cardiologists and cardiac surgeons to Nuclear Cardiology.

\section{REFERENCES}

1. Richardson P, McKenna W, Bristow M, Maisch B, Mautner B, O'Connell J et al. Report of the 1995 World Health
Organization/International Society and Federation of cardiology task force on the definition and classification of cardiomyopathy. Circulation 1996;93(5):841-2. doi:/10.1161/01.cir.93.5.841

2. Nguyen VQ (Jan 20, 2017) Dilated Cardiomyopathy. Retrieved from http://emedicine.medscape.com

3. Matsumori A, Furukawa Y, Hasegawa K, Sato Y, Nakagawa $\mathrm{H}$, Morikawa $\mathrm{Y}$, et al. Epidemiologic and Clinical Characteristics of Cardiomyopathies in Japan: Results from Nationwide Surveys. Circ J 2002; 66(4):323-36. doi:10.1253/circj.66.323

4. WRITING COMMITTEE MEMBERS, Yancy CW, Jessup M, Bozkurt B, Butler J, Casey DE Jr, et al. 2013 ACCF/AHA guideline for the management of heart failure: a report of the American College of Cardiology Foundation/American Heart Association Task Force on practice guidelines. Circulation. 2013; 128(16): e240-327. doi:10.1016/j.jacc.2013.05.019

5. Banerjee SK, Rahman F, Salman M, Siddique MA, Zaman SMM, Anam K et al. Idiopathic Dilated Cardiomyopathy: Clinical Profile of 100 Patients. University Heart Journal 2010; 6 (1): 9-12. doi:10.3329/uhj.v6i1.7182.

6. Juenger J, Schellberg D, Kraemer S, Haunstetter A, Zugck $\mathrm{C}$, Herzog $\mathrm{W}$ et al.. Health related quality of life in patients with congestive heart failure: comparison with other chronic diseases and relation to functional variables. Heart 2002 Mar; 87(3):235-41.doi:10.1136/heart.87.3.235

7. Askoxylakis V, Thieke C, Pleger ST, Most P, Tanner J, Lindel $\mathrm{K}$ et al. Long-term survival of cancer patients compared to heart failure and stroke: A systematic review. BMC Cancer. 2010; 10:105.doi:10.1186/1471-2407-10-105

8. Stewart S, MacIntyre K, Hole DJ, Capewell S, McMurray JJ. More 'malignant' than cancer? Five-year survival following a first admission for heart failure. Eur J Heart Fail 2001;3(3): 315-322.doi:10.1016/s1388-9842(00)00141-0

9. Lee JH, Lim NK, Cho MC, Park HY. Epidemiology of Heart Failure in Korea: Present and Future. Korean Circ J. 2016;46(5):658-664.doi:10.4070/kcj.2016.46.5.658

10. Matsumura Y, Takata J, Kitaoka H, Kubo T, Baba Y, Hoshikawa E et al. Long-term Prognosis of Dilated Cardiomyopathy Revisited - An Improvement in Survival Over the Past 20 years. Circ J 2006;70(4):37683.doi:10.1253/circj. 70.376

11. Kubo T, Matsumura Y, Kitaoka H, Okawa M, Hirota T, Hamada $\mathrm{T}$ et al. Improvement in prognosis of dilated cardiomyopathy in the elderly over the past 20 years. J. Cardiol 2008;52(2):111-7.doi:10.1016/j.jjcc.2008.06.001

12. Pereira Nunes Mdo C, Barbosa MM, Ribeiro AL, Amorim Fenelon LM, Rocha MO. Predictors of Mortality in Patients with Dilated Cardiomyopathy: Relevance of Chagas Disease as an Etiological Factor. Rev Esp Cardiol 2010;63(7):78897.doi:10.1016/s1885-5857(10)70163-8

13. Kwon DH, Hachamovitch R, Popovic ZB, Starling RC, Desai 
MY, Flamm SD et al. Survival in Patients with Severe Ischemic Cardiomyopathy Undergoing Revascularization Versus Medical Therapy: Association with End-Systolic Volume and Viability. Circulation 2012;126(11 Suppl 1):S38. doi:10.1161/circulationaha.111.084434

14. Romero-Farina G, Candell-Riera J, Galve E, Armadans L, Ramos F, Castell J et al. Do Myocardial perfusion SPECT and radionuclide angiography studies in adult patients with hypertrophic cardiomyopathy have prognostic implications? J Nucl Cardiol 2004; 11(5):578-86.

doi:10.1016/j.nuclcard.2004.05.008

15. Bourque JM, Charlton GT, Holland BH, Belyea CM, Watson DD, Beller GA. Prognosis in patients achieving $\geq 10$ METS on exercise stress testing: was SPECT imaging useful? J Nucl Cardiol 2011;18(2):230-7. doi:10.1007/s12350-010-9323-2

16. Shaw LJ, Iskandrian AE. Prognostic value of gated myocardial perfusion SPECT. J Nucl Cardiol 2004;11(2):171-85. doi:10.1016/j.nuclcard.2003.12.004

17. Abidov A, Germano G, Hachamovitch R, Berman DS. Gated SPECT in assessment of regional and global left ventricular function: major tool of modern nuclear imaging. J Nucl Cardiol, 2006;13(2):261-79. doi:10.1016/j.nuclcard.2006.02.003

18. Senior R, Kaul S, Raval U, Lahiri A. Impact of revascularization and myocardial viability determined by nitrate-enhanced Tc-99m sestamibi and Tl-201 imaging on mortality and functional outcome in ischemic cardiomyopathy. J Nucl Cardiol. 2002;9(5):454-62. doi:10.1067/mnc.2002.123913

19. Nasreen F, Nisa L, Sarker AK, Kabir MF. Journey of Nuclear
Cardiology in Bangladesh - A report. Bangladesh J Nucl Med 2009;12(1):108

20. Balu V, Szmedra L, Dean D, Bhayana J. Long-Term Survival of Patients with Low Ejection Fraction Surgical versus Medical Management. Tex Heart Inst J 1988;15(1):44-8. PMID: 15227278

21. Romero-Farina G, Candell-Riera J, Aguadé-Bruix S, de LeónG, Castell-Conesa J. Effect of Coronary Revascularization in Patients with Ischemic Cardiomyopathy who Satisfy Viability Criteria on Gated-SPECT Assessment of Myocardial Perfusion. Rev Esp Cardiol. 2008; 61(5):540-4. doi:10.1016/s18855857(08)60169-3

22. Velazques EJ, Lee KL, Deja MA, Jain A, Sopko G, Marchenko A et al. Coronary-Artery Bypass Surgery in Patients with Left Ventricular Dysfunction. N Engl J Med 2011; 364(17):1607-16. doi: 10.1056/NEJMoa1100356

23. Bonow RO, Maurer G, Lee KL, Holly TA, Binkley PF, Desvigne-Nickens $P$ et al. Myocardial Viability and Survival in Ischemic Left Ventricular Dysfunction. N Engl J Med 2011;364(17):1617-25. doi: 10.1056/NEJMoa1 100358

24. Allman KC, Shaw LJ, Hachamovitch R, Udelson JE. Myocardial Viability Testing and Impact of Revascularization on Prognosis in Patients With Coronary Artery Disease and Left Ventricular Dysfunction: A MetaAnalysis. J Am Coll Cardiol 2002; 39(7): 1151-8. doi:10.1016/s0735-1097(02)01726-6

25. Inaba Y, Chen JA, Bergmann SR. Quantity of viable myocardium required to improve survival with revascularization in patients with ischemic cardiomyopathy: A meta-analysis. J Nucl Cardiol 2010;17(4): 646-54. doi:10.1007/s12350-010-9226-2 